\title{
ОСУЖДЕНИЕ ОРИГЕНОВСКОГО УЧЕНИЯ О ПРЕДСУЩЕСТВОВАНИИ И ПЕРЕСЕЛЕНИИ ДУШ В IV-VI ВВ.
}

\section{CONDEMNATION OF ORIGEN'S DOCTRINE ABOUT THE PRE-EXISTENCE OF SOULS AND REINCARNATION IN THE 4th - 6th CENTURIES A. D.}

\author{
И.В. Зайцева \\ I.V. Zaitseva \\ Белгородский юридический институт Министерства внутренних дел Российской Федерации \\ имени И.Д. Путилина, \\ Россия, 308024, г. Белгород, ул. Горького, 71
}

Belgorod Law Institute of Ministry of the Internal of the Russian Federation named after I.D. Putilin, 71 Gorkiy St, Belgorod, 308024, Russia

E-mail: zajcevil@mail.ru

\begin{abstract}
Аннотация
В качестве основной цели данной статьи выступает анализ процесса осуждения взглядов Оригена относительно идеи реинкарнации и предсуществования души в IV-VI веках. Хронологические рамки объективно обуславливают структуру работы. С опорой на исторические факты автор статьи показывает, что при жизни создателя оригеновское учение сразу не подвергалось прямому осуждению, однако к IV веку отношение к Оригену и его взглядам изменяется. К числу основных оппонентов оригеновского учения следует отнести Памфила Мученика, Епифания Кипрского, епископа Александрийского Феофила. Наиболее ярко оригенистские споры проявили себя в VI веке на двух соборах, которые проходили в Константинополе в 543 и 553 годах. При этом подчеркивается, что ни один собор прямо не осудил учение Оригена по вопросу о предсуществовании и переселении душ.
\end{abstract}

\begin{abstract}
The article analyzes the issues of condemnation of the doctrine of Origen. The analysis of the topic of the research based on the works of church historians Socrates Scholasticus, Evagrius Scholasticus, ecclesiastical writer Jerome of Stridonium, antiheretic Epiphanius of Salamis, Photius I of Constantinople and on the works of Origen. On the basis of historical facts, the authors showed that in the time of life of Origen his doctrine had never been condemned in connection with any of its provisions. However, in the V-VI centuries denunciation of Origen have begun to emerge among Christian theologists. Certain preconditions of the beginning of the condemnation was that Origen himself ambiguously had suggested that souls transmigrate to another body according to their deeds in a previous life. Originally, although indirectly, he adhered to reincarnation, but later he had begun to criticized this concept, this has given rise to accusation from his opponents. Opponents proved that Origen had adhered to the pre-existence of soul based on the Origen's works, for example, «On the First Principals». Furthermore, as reflected in the article, liberal interpretations of ideas of Origen by representatives of various heretical currents had distorted numerous provisions of his doctrine, which had been referred to by himself in the time of his life. The origenian disputes had been especially true in VI century at two Ecumenical Councils, that took place in Constantinople in 543 and 553 at the initiative of Justinian the Great. In addition, the authors note that none of Ecumenical Councils has condemned the doctrine of Origen.
\end{abstract}

Ключевые слова: Ориген, оригеновские споры, предсуществование души, реинкарнация, Пятый Вселенский собор, Александрийская школа.

Keywords: Origen, origenian disputes, the pre-existens of souls, reincarnation, Fifth Ecumenical Council, the school of Alexandria. 
Личность Оригена - крупнейшего христианского богослова (ок. 185-254) [Clark, 1987; Crouzel, 1989; Clark, 1992; Gasparro, 2003], доникейского «отца церкви», руководителя школы в Александрии и Кесарии - еще при его жизни вызывала большое количество споров. Хронология рассматриваемого вопроса обусловлена тем, что именно в этот период происходит выделение в среде крупных интеллектуалов группы последователей учения Оригена и его оппонентов, а также тем фактом, что в IV-VI вв. осуждение оригеновского учения имело интересную активную динамику, причем не только в контексте своей содержательной части, но и в рамках трансформации отношения к учению в разрезе взглядов отдельных христианских богословов.

Предметом исследования в статье выступает само учение Оригена о предсуществовании и переселении душ, а также процесс его осуждения высшими церковными иерархами в рассматриваемый период времени. Выбор данного предмета определяется тем, что вопросы «миграции» души и её существования до переселения в тело представляются наиболее полемичными во всем оригеновском учении как в период поздней античности, так и в исследованиях современных западных и отечественных ученых.

Ориген жил в Александрии - городе, который на протяжении нескольких веков сохранял статус интеллектуальной Мекки античности, сочетавший в себе различные элементы научной и религиозной эклектики. Подобное обстоятельство не могло не отразиться на взглядах Оригена, которые постепенно трансформировались от строгой ортодоксальности к культурно-религиозной эклектике, хотя и скрытого толка [Chadwick, 1966; Scott, 1991]. Кроме того, Ориген был учеником Климента Александрийского и, как сообщает Евсевий Кесарийский, возможно, Аммония Саккаса (Euseb., Hist. eccl. VI) [Hornschuh, 1960, p. 1-25, 193-214; Theiler, 1966, p. 1-45; Edwards, 1993, p. 1-43; Barbanti, 2002, p. 355-373; Digeser, 2012; Hanson, 2015], вследствие чего мог целенаправленно стремиться к продолжению работы по синтезированию христианства и язычества.

На первых этапах своей профессиональной деятельности Ориген пользовался большим уважением в христианском сообществе (Euseb., Hist. eccl. VI) [Cadiou, 1935, p. 184-198]. Авторитет Оригена был заметен не только в среде мирян, но и у александрийского духовенства. Подтверждением этому является тот факт, что александрийский епископ Димитрий назначил Оригена руководителем Александрийской школы ${ }^{1}$. Ухудшение отношений между Димитрием и Оригеном стало первым сигналом к последующему осуждению Оригена. Поскольку мы придерживаемся той точки зрения, что Ориген за свое учение при жизни осужден не был, отдельное внимание вопросу прижизненного опровержения взглядов александрийского мыслителя в рамках данной статьи не уделяется ${ }^{2}$.

Постепенно рост авторитета александрийского мыслителя привел к тому, что на оригеновское учение стали ссылаться представители отдельных религиозных течений для подтверждения собственных воззрений (Euseb., Hist. eccl. VI). Попытки Оригена «сбалансировать» христианство и язычество вынуждали и тех, и других обращаться к его трудам, выбирая именно то, что подчеркивало их собственные идеи. Постепенно стали распространяться книги, представлявшие собой компиляции взглядов Оригена в произвольной форме ${ }^{3}$.

Своеобразной точкой отсчета в формировании оригеновской оппозиции стал трактат Памфила Мученика «Апология Оригена», который являлся ответом на письмо испо-

${ }^{1}$ На это прямо указывает Евсевий: «Оригену было 18 лет, когда он стал во главе училища для оглашаемых, ... а труд оглашения поручен епископом Димитрием ему одному ...» (Euseb., Hist. eccl. VI).

${ }^{2}$ В данном случае мы полагаем, что причины противостояния были связаны не с догматическими взглядами Оригена, а с тем, что Димитрий и Ориген по-разному смотрели на канонические правила, принятые в Александрийской церкви.

${ }^{3}$ Сам Ориген об этом писал следующим образом: «Если кто верит мне, который говорит пред лицом Самого Бога, тот пусть верит и в том, что говорю я о вымыслах и вставках, внесенных в письмо мое; а кто не верит, но хочет говорить обо мне худо, тот будет лжесвидетелем пред Богом». Ссылку на это мы находим у его «главного» переводчика Руфина. Иероним, пребывая в Кесарии, имел возможность ознакомиться с письмами Оригена, поэтому осознавал, что история с подлогом вполне достоверна. 
ведников, находившихся на рудниках в Фэно ${ }^{4}$. До издания Константином Медиоланского эдикта исповедники-пустынножители пользовались среди христиан большей популярностью, чем церковный клир. Для того чтобы оправдать себя в их глазах ${ }^{5}$, Памфил пишет свою «Апологию», обращая внимание на главное, по его мнению, место расхождения взглядов Оригена и пустынножителей - вопрос реинкарнации. Интересен тот факт, что в большей своей части книга посвящена доказательству того, что Ориген не проповедовал идею реинкарнации, но при этом в работе явно существовали попытки найти обратные доказательства. Возможно, сами исповедники были к этому причастны. Если на самом деле в роли обвинителей здесь выступали исповедники, то степень доверия к ним в отношении критики реинкарнации Оригена существенно снижается, поскольку маловероятно, что им были доступны сочинения христианского учителя, а, следовательно, они узнавали о его идеях по пересказам. При этом некоторые авторы обращают внимание на то, что и сам Памфил не имел доступа к трудам Оригена, чтобы дать им подробный анализ, в том числе и по рассматриваемому предмету. Однако после смерти Памфила «Апологию» дописывал Евсевий, ставший епископом Кесарийским, что означало автоматическое получение доступа к литературному наследию Оригена ${ }^{6}$. Кроме того, в распоряжении Евсевия была личная переписка и воспоминания Оригена, которые сохранили ученики мыслителя из Александрии и Кесарии. Стоит отметить, что сохранившиеся фрагменты «Апологии» скорее подтверждают то, что Ориген не придерживался идеи реинкарнации, поскольку Евсевий и Памфил являлись её последователями, и если бы подобные теории были близки Оригену, то или Памфил, или Евсевий упомянули бы об этом, подтверждая собственные воззрения [Edwards, 1995, p. 502-518].

Одним из первых оппонентов Оригена в IV веке был Епифаний Кипрский, который две главы своего труда «Панарион» назвал «Об Оригене, который зовется Адамантовым» и «Об оригенистах первых - они же срамные». Здесь мы встречаем одно из первых употреблений термина «оригенисты», но примечательно, что сам автор не знает, кого именно он к ним относит: «Некоторые еретики называются оригенистами; этот род ереси находится не везде. По моему мнению, и эта ересь явилась вслед за теми ересями. А отчего именуются они оригенистами, не совсем ясно мы знаем, - от Оригена ли Адамантового, прозванного Синтактом (сочинителем), или от кого-нибудь другого, - не знаю. Впрочем, это название у нас принято» (Epiph. Cypr. Panar.).

Вначале Епифаний дает положительную оценку личности Оригена, указывая на его подвижническую жизнь, образованность и авторитет в обществе. Однако ниже он отмечает, что основной причиной, по которой Ориген оказался в ситуации опровержения, стало его нежелание пояснять смысл сказанного (Epiph. Cypr. Panar. 64). Очевидно, Епифаний выделял несколько (как минимум две) групп оригенистов: одних он причислял к последователям самого Оригена, не наделяя их негативными чертами, а вторых называл «срамными», но не определял их прямого отношения к Оригену (Epiph. Cypr. Panar.). Самым серьезным обвинением Епифания стало то, что ересь Оригена, по его мнению, касалась сомнения относительно Божества и давала повод к возникновению арианской ереси (Epiph. Cypr. Panar.). На связь Оригена с истоками арианства указывает и Иероним Стридонский в письме к Паммахию и Океану: «Исповедали то, что отрицалось, и о том, о чем никто не спорил, умолчали, хотя косвенно осудили Оригена как источник Ария; ибо, осуждая отвергавших, что Сын есть от существа Отчего, осудили равно его и Ария» [Ориген и Св. Предание... 2010, с. 25].

\footnotetext{
${ }^{4}$ Пустыня к югу от Мертвого моря.

${ }^{5}$ Исповедники не принимали учение Оригена.

${ }^{6}$ После того, как Ориген покинул Александрию, соблюдая решения собора, созванного Димитрием, он переселился в Кесарию Палестинскую, где написал значительное количество трудов, которые бережно сохраняли кесарийские епископы, в частности, епископ Александр.
} 
Более очевидными оригеновские реинкарнационные споры становятся в V веке. Начало им было положено епископом Александрии Феофилом, который в Пасхальном послании выдвинул обвинение против Оригена в том, что тот поддерживал идею о переселении душ [Болотов, 1999, с. 402; Jacobsen, 2003, p. 649-656]. Интересен тот факт, что изначально Феофил был, скорее, оригенистом. Так, он выступал с критикой так называемых антропоморфитов, представлявших Бога в чувственном, телесном образе, о чем он упомянул в Пасхальном послании 399 г. Однако идеи телесности Бога придерживались монахи, жившие в пустыне, у которых это послание вызвало возмущение. Чтобы избежать монашеского недовольства и, возможно, даже расправы над собой, Феофил принял сторону противников Оригена. В отношении того, почему Феофил поменял свою позицию относительно оригеновского учения, существуют и иные версии, однако это должно стать предметом специального исследования.

Последователь и племянник Феофила Кирилл Александрийский в отношении Оригена придерживался аналогичных взглядов. Так, обращаясь к монахам, проживавшим в Фуе, он отмечал, что Ориген извратил истину и впал в заблуждение [Ориген и Св. Предание... 2010, с. 16]. В данном послании упоминается и ключевая причина этого «заблуждения»: «....Ибо он говорит, что души существовали прежде тел, и от дел святых они увлеклись в злые похоти и удалились от Бога, а за это Он осудил их и отелесил, и они находятся во плоти, как в темнице» [Ориген и Св. Предание... 2010, с. 16].

Официальное осуждение Оригена состоялось в конце 399 - начале 400 г. на соборе в Александрии, который был созван по инициативе патриарха Феофила [Banev, 2015, p. 35-36]. Сохранились сведения о вынесении данного решения в посланиях Феофила, в которых сообщается, что сочинения Оригена были осуждены в присутствии монахов и епископов [Banev, 2015, p. 37]. Палладий, напротив, утверждал, что епископы были лишены возможности высказать свое мнение, поскольку Александрийский епископ, согласно церковному праву Египта, имел право единоличного принятия решений [Banev, 2015, p. 37].

После проведения собора патриарх обратился к Римскому папе Анастасию I, официально утвердившему осуждение. Обращает на себя внимание второе синодальное послание Феофила к епископам Палестины и Кипра, в котором он указывает на то, что Нитрийский собор единогласно осудил такие книги Оригена, как «О началах», «О молитве» и «О воскрешении». В тексте послания Феофил указал, что его стремление к осуждению оригеновских взглядов производится не на основе умозрительных обвинений и слухов, а в ходе точного и справедливого расследования. Подобные заключения, по большей части, представляют собой желание Феофила оправдать свои действия в глазах церковного клира и монахов целесообразностью и разумностью осуществляемых поступков.

Роль Феофила в осуждении учения Оригена достаточно очевидна. Пытаясь укрепить свою власть, значительная доля патриархов, в том числе и александрийских, фактически выбирала для себя оппонента с целью развенчать мифы об авторитетности того или иного автора. Такая традиция оппонирования в ранних богословских спорах автоматически приводила церковных иерархов к закреплению тех догматов, с помощью которых им было легче удерживать свою власть. Стоит отметить, что на протяжении V века о какихлибо серьезных предметных дискуссиях относительно учения Оригена у других христианских богословов мы не слышим [Диакон Андрей Кураев, 2001] ${ }^{7}$.

Особого внимания заслуживают оригеновские споры VI века, поскольку в этот период они уже носили не просто интеллектуальный, а стали приобретать институциональный характер. Начало им было положено на Пятом Вселенском соборе, проходившем в Константинополе в 553 г. Собор был созван по инициативе императора Юстиниана. Вер-

7 Лишь один эпизод с указанием на околоцерковность взглядов Оригена мы находим у Захарии Ритора в «Церковной истории» и несколько неубедительных аргументов у Антипатра Бострийского в его «Опровержении Апологии Евсевия Кесарийского в защиту Оригена». Оба произведения датируются примерно 440-ми гг. 
сия о том, что Пятый Вселенский собор был посвящен осуждению Оригена, берет свое начало с «Хронографии» Феофана Исповедника, который писал, что «в этом году был святой и вселенский пятый Собор против Оригена суемудренного и Дидима невидящего, и Евагрия, и их еллино-мудренной болтовни, а равно и против безглавых глав» [Диакон Георгий Максимов, 2013; Летопись Византийца Феофана от Диоклетиана..., 1884, с. 176]. Именно тот факт, что Ориген стоит первым в ряду богословов, преданных анафеме, и стал поводом к разворачиванию тезиса о том, что собор был созван «ради» Оригена.

Основной целью созыва собора было решение вопроса о справедливости учения трех несторианских епископов - Феодора Мопсуестийского, Феодорита Кирского и Ивы Эдесского. Созыв собора объяснялся тем, что Халкидонский собор 451 г., осудив монофизитов и несториан, не осудил этих трех епископов, что вызывало подозрения в сочувствии православных иерархов Константинопольской и других церквей несторианам. Для того чтобы устранить поводы для домыслов, император Юстиниан издал указ, в котором отдельные главы были посвящены осуждению трех епископов, но поскольку данный указ не был признан представителями Западной церкви и церкви в Африке, возникла необходимость созыва собора для решения спора о так называемых «Трех главах».

На Соборе присутствовало 165 епископов под руководством патриарха Константинопольского Евтихия ${ }^{8}$. Дело о «Трех главах» рассматривалось на восьми заседаниях собора, которые проходили с 4 мая по 2 июня 553 г. Относительно самого повода созыва собора следует упомянуть, что анафеме официально был предан Феодор Мопсуестийский, а Феодорит Кирский и Ива Эдесский были осуждены лишь за отдельные сочинения.

Исходя из вышесказанного, очевидно, что ни одно заседание собора не было проведено специально для осуждения Оригена. Его имя упоминалось на соборе дважды - в рамках 5-го и 8-го заседаний. На пятом заседании он упоминался как один из тех представителей-еретиков, которые подлежат осуждению. На восьмом заседании подтверждалось осуждение и анафематствование Оригена, а помимо него еще Ария, Евномия, Македония, Аполлинария, Нестория, Евтихия [Ориген и Св. Предание..., 2010, с. 214]. Стоит отметить, что если предположить, что все они были подвергнуты осуждению за свои размышления о перерождении души, то это явно бездоказательно, учитывая, что никого из них (кроме Оригена) в этом не обвиняли. Следовательно, собор не созывался для осуждения учения Оригена о переселении душ. Кроме того, если говорить о том, что Ориген был предан анафеме за подобные размышления, то это тоже вряд ли можно назвать реальным поводом для созыва вселенского собора. Вероятнее всего, собор просто подтвердил раннее осуждение Оригена. В послесоборных посланиях ${ }^{9}$ также нет упоминаний об осуждении Оригена, оригенизма или его учения о переселении душ.

Диакон Георгий Максимов в своей статье «Пятый Вселенский собор и осуждение оригенизма» выдвигает несколько иную версию [Диакон Георгий Максимов, 2013]. Со ссылкой на Евагрия Схоластика он упоминает смуту в Палестине, возникшую из-за монахов оригенистской направленности, которым покровительствовал Феодор Аскида, приближенный к императору Юстиниану [Диакон Георгий Максимов, 2013; Egmond, 2013, p. 631-647] ${ }^{10}$. Для того чтобы отвлечь внимание императора от смуты, Феодор перевел вектор на Феодора Мопсуестийского, Феодорита Кирского и Иву Эдесского, тем самым

8 Примечательно, что папа Римский Вигилий отказался участвовать в соборе, несмотря на неоднократное официальное приглашение и личное присутствие в Константинополе. В результате император наказал Вигилия отлучением от церкви. Несмотря на то, что в дальнейшем папа Римский согласился с постановлением собора, долгое время вся область Аквилейского митрополита находилась в состоянии раскола.

${ }_{9}^{9}$ Собрания, которые посылали участники собора отсутствующим епископам с целью уведомления о соборных решениях.

10 А.В. Карташев указывает на то, что Феодор Аскида относился к монахам палестинских монастырей Мар-Саба (т. е. св. Саввы) и Новой Лавры в Фекое (Текуа) около Вифлеема, которые увлеченно поддерживали оригеновские идеи о предсуществовании и переселении душ [Карташев, 2002]. 
неожиданно для себя приведя церковную власть к осуждению Оригена [Диакон Георгий Максимов, 2013].

Несмотря на то, что сочинение Евагрия Схоластика дает нам несколько большую почву для размышлений, все же мы видим, что упоминание Оригена как еретика проходит второй, если не третьей темой на соборе. И, безусловно, мы в очередной раз можем подтвердить тезис о том, что учение Оригена о переселении душ на нем специально не рассматривалось. Относительно же роли Феодора Аскиды в созыве Пятого Вселенского собора можно предположить, что его действия были лишь предпосылкой осуждения оригеновского учения. Гораздо очевиднее, что процесс осуждения учения Оригена начался с Юстиниана, который преследовал куда более глобальные цели: устраняя очаги еретических движений, он пытался сплотить империю и укрепить государственную власть.

Другие исследователи отмечают, что собор, на котором были произнесены обличительные речи против Оригена, состоялся в 543 г. по обращению Саввы Освященного к императору Юстиниану с просьбой побороть беспорядки, которые устроили в его монастыре оригенисты [Egmond, 2013, p. 631-647]. Император изучил сочинения Оригена и отправил послание константинопольскому патриарху Мине с распоряжением осудить оригеновское учение. Здесь следует отметить, что, несмотря на то, что Юстиниан воспринял работы александрийского мыслителя как еретические, он не сделал ни одной пометки относительно убежденности Оригена в переселении душ. Безусловно, сам факт отсутствия замечаний по этому вопросу Юстиниана есть argumentum ex silentio, однако следует предположить, что именно такое размытое осуждение, вне контекста и без привязки к определенным положениям учения, отразилось на самом характере осуждения.

Полагаем, что версия о том, что Ориген обвинялся в «пособничестве идеи реинкарнации», связана с посланием 553 г., которое Юстиниан отправил участникам собора и отметил, что осуждающе относится к теме реинкарнации, которую в своих работах инициировали Пифагор, Платон и Плотин (то есть фактически были выдвинуты обвинения против всего неоплатонизма и неопифагорейства) [Вӧhm, 2002, p. 7-23]. Следует считать данную аргументацию вполне логичной, поскольку к этому периоду неоплатонизм все чаще стал подвергаться нападкам со стороны христианских властей.

В целом относительно темы осуждения оригенизма на Пятом Вселенском соборе можно сказать, что, вероятно, на соборе была подтверждена ересь Оригена посмертно, однако тема реинкарнации не поднималась. Дальнейшие обвинения Оригена в приверженности идее реинкарнации были связаны с тем, что церковь укрепляла свои позиции и называла еретическими все учения, в которых прямо или косвенно имели место тезисы, не соответствующие ортодоксальной доктрине. Причем, следует заметить, что последующие церковные иерархи субъективно-выборочно подходили к оценке учений того или иного автора, иначе сложно объяснить, почему тезисы о предсуществовании души и даже реинкарнации встречаются опосредованно у многих богословов (например, у Дионисия Александрийского), однако анафеме были подвергнуты не все они. Очевидно, что Константинопольские соборы осудили предпосылки, на которых могла строиться оригеновская доктрина реинкарнации ${ }^{11}$, но с формальной точки зрения само учение о переселении душ осуждено не было.

В отечественной науке существуют и существовали версии о том, что учение Оригена было осуждено еще до открытия собора [Поснов, 1964, с. 443]. Однако очевидно, что осуждение учения и официальная анафема богослова - это несколько разные вещи. В целом большая часть авторов склоняется к версии о том, что собор не осуждал учение Оригена и не предавал анафеме саму его личность.

11 Поскольку если нет предсуществования душ, если душа творится вместе с телом, то и предшествующих жизней также не существует. 
Тем не менее сама идея реинкарнации опосредованно содержалась в работе Оригена «О началах». Обратим внимание на следующие цитаты: «только этим учением ${ }^{12}$ и можно защитить правду Божью во всех распоряжениях Бога относительно этих тварей, потому что по этому учению каждая тварь в самой себе имеет причины того, что она находится в том или ином порядке жизни» [Ориген, 2008, с. 282], или ««Умирающие здесь обыкновенною смертью распределяются на основании дел, совершенных здесь, так что признанные достойными так называемой адской страны получают разные места, соответственно своим грехам. Также, может быть, и те, которые, так сказать, умирают там (на небе), нисходят в этот ад, признанные достойными обитать в различных, лучших или худших, жилищах на всем земном пространстве и родиться от таких или иных родителей, так что израильтянин может когда-нибудь попасть в число скифов, а египтянин - перейти в Иудею» [Ориген, 2008, с. 307-308]. В первом случае мы видим указание Оригена на зависимость поступков человека от его жизни, в некотором смысле мы можем полагать, что он имел в виду жизнь земную, если бы не вторая цитата, в которой он прямо указывает на подобную зависимость. Однако в своих последующих произведениях ${ }^{13}$ Ориген, напротив, выступил с резкой критикой реинкарнации: «Допущение метемпсихозы или перевоплощения душ несовместно с кончиной мира, которую ясно утверждает Писание. Ибо если предположим, что всякая душа в течение нынешнего порядка вещей от начала и до конца мира воплощается не более как два раза, спрашивается: зачем она воплощается во второй pa3?» [Origen. Commentary, 2019]. На наш взгляд, такое разноголосье в оценках Оригена, прежде всего, связано с внутренней борьбой Оригена относительно собственных взглядов на реинкарнационные процессы. Поэтому очевидно, что он пытался высказать эту идею вскользь, оставив принятие решений своему читателю. Подобная лояльность в дальнейшем самому Оригену «сослужила плохую службу» и привела к посмертной анафеме.

В заключение следует сделать следующие выводы:

- при жизни Ориген пользовался большим авторитетом как в среде церковных иерархов, так и у александрийской паствы;

- официальное осуждение Оригена состоялось в 543 и 553 гг. на соборах, созванных по инициативе императора Юстиниана, при этом на данных соборах не было осуждено учение о переселении и предсуществовании душ. Все обвинения в основном сводились к ереси Оригена в целом, а не к отдельным фрагментам его учения;

- вопрос относительно того, имели ли место в учении Оригена вопросы реинкарнации и предсуществования души, вероятнее всего, подлежит дальнейшей, более тщательной разработке. Однако мы можем утверждать, что тезис о предсуществовании души встречается в учении Оригена, в частности в его труде «О началах», а реинкарнационное учение имело двоякую трактовку, что, на наш взгляд, подтверждает версию о том, что Ориген в силу своей образованности и эклектики взглядов не мог категорично утверждать идею реинкарнации, но и не отрицал её с должным рвением. Кроме того, Ориген жил в порубежное время и был убежденным христианином, что заставляло его расширять число христианских последователей из представителей языческой среды. В этой связи занимать однозначную позицию по вопросам реинкарнации Ориген явно не мог.

В целом, полагаем, что перманентное стремление Оригена занять разные позиции в рассматриваемом вопросе привело его к дальнейшему осуждению, процесс которого также складывался стихийно. Однако ортодоксальность взглядов и жизненного пути самого Оригена, в некоторых аспектах граничившая с его любовью к античному наследию [Runia, 2003, p. 43-48], не позволила церковным иерархам «освободить» христианского богослова от последующей анафемы [Williams, 1999, p. 3-14].

\footnotetext{
12 Имеется в виду учение о предсуществовании душ.

${ }^{13}$ В частности, имеем в виду «Толкование на Матфея».
} 


\section{Список литературы}

1. Болотов В.В. 1879. Учение Оригена о Святой Троице. СПб., Тип. Ф.Г. Елеонского и $\mathrm{K}^{\circ}, 452$.

2. Диакон Андрей Кураев. 2001. Раннее христианство и переселение душ. https://azbyka.ru/rannee-xristianstvo-i-pereselenie-dush\#b645 (дата обращения: 05.01.2020)

3. Диакон Георгий Максимов. 2013. Пятый Вселенский собор и осуждение оригенизма. http://www.pravoslavie.ru/63080.html (дата обращения: 05.01.2020)

4. Карташев А.В. 2002. Император Юстиниан I Великий (527-565 гг.) и V Вселенский собор / Вселенские соборы. https://azbyka.ru/otechnik/Anton_Kartashev/vselenskie-sobory/ (дата обращения: 05.01.2020)

5. Летопись Византийца Феофана от Диоклетиана до царей Михаила и сына его Феофилакта. 1884-1887. В пер. с греч. В.И. Оболенского и Ф.А. Терновского; с предисл. О.М. Бодянского. М., Университетская типография, 370.

6. Ориген. 2008. О Началах. Против Цельса. М., Библиополис, 792.

7. Ориген и Св. Предание. Святые отцы и православные богословы об Оригене. 2010. Сост. свящ. Алексий Петухов. СПб., Аксион эстин, 43.

8. Поснов М.Э. 1964. История христианской Церкви (до разделения Церквей - 1054). Брюссель, Жизнь с Богом, 614.

9. Banev K. 2015. Theophilus of Alexandria and the First Origenist Controversy: Rhetoric and Power. Oxford, Oxford University Press, 256.

10. Barbanti M. 2002. Origene di Alessandria e la scuola di Ammonio Sacca. HENOSIS KAI PHILIA = Unione e amicizia: Omaggio a Francesco Romano. Ed. by Maria Barbanti, Giovanna Rita Giardina, Paolo Manganaro. Catania, CUECM, 355-373.

11. Böhm T. 2002. Origenes, Theologe und (Neu-) Platoniker? Oder: wem soll man misstrauen, Eusebius oder Porphyrius? Adamantius, 8: 7-23.

12. Cadiou R. 1935. La jeunesse d'Origène: Histoire de l'école d'Alexandrie au début du IIIe siècle. Etudes de Théologie Historique, 17: 184-198.

13. Chadwick H. 1966. Early Christian Thought and the Classical Tradition: Studies in Justin, Clement, and Origen. Oxford, Oxford University Press, 512.

14. Clark E.A. 1987. The Place of Jerome's Commentary on Ephesians in the Origenist Controversy: The Apokatastasis and Ascetic Ideals. Vigiliae Christianae. Vol. 41, № 2: 154-171.

15. Clark E.A. 1992. The Origenist Controversy: The Cultural Construction of an Early Christian Debate. Princeton, Princeton University Library, 287.

16. Crouzel H. 1989. Origen: The Life and Thought of the First Great Theologian. San Francisco, 278.

17. Digeser E. 2012. A threat to public piety: Christians, Platonists, and the great persecution. Cornell, 218.

18. Edwards M.J. 1993. Ammonius, Teacher of Origen. Journal of Ecclesiastical History, 44: $1-43$.

19. Edwards M.J. 2002. Origen against Plato. Ashgate, 191.

20. Edwards M.J. 1995. Origen's Two Resurrections. Journal of Theological Studies, 46: $502-518$.

21. Egmond P. van. 2013. Pelagius and the Origenist Controversy in Palestine. Studia Patristica. Vol. LXX. Leuven - Paris, Peeters, 631-647.

22. Gasparro G. 2003. Origene e la magia: teoria e prassi. Origeniana VIII. Origen and the Alexandrian tradition. Ed. L. Perrone. Vol. I-II. Leuven, University press, 733-756.

23. Hanson R. 2015. Origen's Doctrine of Tradition. Cambridge, Cambridge University Press, 260.

24. Hornschuh M. 1960. Das Leben des Origenes und die Entstehung der alexandrinischen Schule. ZKG. 71, 1-25: 193-214.

25. Jacobsen A.-C. 2003. Origen on the Human Body. Origeniana VIII. Origen and the Alexandrian tradition. Ed. L. Perrone. Vol. I-II. Leuven, University press, 649-656.

26. Nautin P. 1977. Origene. Sa vie et son oeuvre. Paris, Edition, 474.

27. Origen. Commentary on the Gospel of Matthew. 2019. From Ante-Nicene Fathers, Vol. 9. Ed. by Allan Menzies. Buffalo, NY, Christian Literature Publishing Co. http://www.newadvent.org/fathers/1016.htm 
28. Runia D. 2003. Origen and Hellenism. Origeniana Octava. Origen and the Alexandrian tradition. Ed. L. Perrone. Vol. I-II. Leuven, University press, 43-48.

29. Scott A.B. 1991. Origen and the Life of Stars. Oxford, University Press, 189.

30. Theiler W. 1966. Ammonios der Lehrer des Origenes. Forschungen zum Neoplatonismus. Ed. by W. Theiler. Berlin, de Gruyter, 1-45.

31. Williams R.D. 1999. Origen between Orthodoxy and Heresy. Origeniana Septima. Leuven, $3-14$.

\section{References}

1. Bolotov V.V. 1879. Uchenie Origena o Svyatoj Troice [The Teaching of Origen on the Holy Trinity]. Saint Petersburg, Tipografiya F.G. Eleonskogo i K 452.

2. D'akon Andrey Kuraev. 2001. Rannee hristianstvo i pereselenie dush [Early Christianity and the transmigration of souls]. Available at: https://azbyka.ru/rannee-xristianstvo-i-pereselenie-dush\#b645 (accessed: 05.01.2020)

3. D'akon Georgiy Maksimov. 2013. Pyatyj Vselenskij sobor i osuzhdenie origenizma [The Fifth Ecumenical Council and the condemnation of Origenism]. Available at: http://www.pravoslavie.ru/63080.html (accessed: 05.01.2020)

4. Kartashev A.V. 2002. Imperator Yustinian I Velikij (527-565 gg.) i V Vselenskij sobor [Emperor Justinian I Great (527-565) and V Ecumenical Council]. Available at: https://azbyka.ru/otechnik/Anton_Kartashev/vselenskie-sobory (accessed: 05.01.2020)

5. Letopis' Vizantijca Feofana ot Diokletiana do carej Mihaila i syna ego Feofilakta 1884-1887 / V per. s grech. V.I. Obolenskogo i F.A. Ternovskogo; S predisl. O.M. Bodyanskogo [Chronicle of the Byzantine Theophanes from Diocletian to the kings Michael and his son Theophylact]. Moscow, Universitetskaya tipografiya, 370 .

6. Origen. 2008. O Nachalah. Protiv Cel'sa [About the beginning. Against Celsus]. Moscow, Bibliopolis, 792.

7. Origen i Sv. Predanie. Svyatye otcy i pravoslavnye bogoslovy ob Origene. 2010. Sost. svyashch. Aleksij Petuhov [Origen and St. Tradition. The Holy fathers and Orthodox theologians on the Origen]. Saint Petersburg, Aksion estin, 43.

8. Posnov M. Je. 1964. Istoriya hristianskoj Cerkvi (do razdeleniya Cerkvej - 1054) [The history of the Christian Church (before the separation of the Churches - 1054)]. Brjussel', Zhizn' s Bogom, 614.

9. Banev K. 2015. Theophilus of Alexandria and the First Origenist Controversy: Rhetoric and Power. Oxford, Oxford University Press, 256.

10. Barbanti M. 2002. Origene di Alessandria e la scuola di Ammonio Sacca. HENOSIS KAI PHILIA = Unione e amicizia: Omaggio a Francesco Romano. Ed. by Maria Barbanti, Giovanna Rita Giardina, Paolo Manganaro. Catania, CUECM, 355-373.

11. Böhm T. 2002. Origenes, Theologe und (Neu-) Platoniker? Oder: wem soll man misstrauen, Eusebius oder Porphyrius? Adamantius, 8: 7-23.

12. Cadiou R. 1935. La jeunesse d'Origène: Histoire de l'école d'Alexandrie au début du IIIe siècle. Etudes de Théologie Historique, 17: 184-198.

13. Chadwick H. 1966. Early Christian Thought and the Classical Tradition: Studies in Justin, Clement, and Origen. Oxford, Oxford University Press, 512.

14. Clark E.A. 1987. The Place of Jerome's Commentary on Ephesians in the Origenist Controversy: The Apokatastasis and Ascetic Ideals. Vigiliae Christianae. Vol. 41, № 2: 154-171.

15. Clark E.A. 1992. The Origenist Controversy: The Cultural Construction of an Early Christian Debate. Princeton, Princeton University Library, 287.

16. Crouzel H. 1989. Origen: The Life and Thought of the First Great Theologian. San Francisco, 278 .

17. Digeser E. 2012. A threat to public piety: Christians, Platonists, and the great persecution. Cornell, 218.

18. Edwards M.J. 1993. Ammonius, Teacher of Origen. Journal of Ecclesiastical History, 44: $1-43$.

19. Edwards M.J. 2002. Origen against Plato. Ashgate, 191.

20. Edwards M.J. 1995. Origen's Two Resurrections. Journal of Theological Studies, 46: $502-518$. 
21. Egmond P. van. 2013. Pelagius and the Origenist Controversy in Palestine. Studia Patristica. Vol. LXX. Leuven - Paris, Peeters, 631-647.

22. Gasparro G. 2003. Origene e la magia: teoria e prassi. Origeniana VIII. Origen and the Alexandrian tradition. Ed. L. Perrone. Vol. I-II. Leuven, University press, 733-756.

23. Hanson R. 2015. Origen's Doctrine of Tradition. Cambridge, Cambridge University Press, 260.

24. Hornschuh M. 1960. Das Leben des Origenes und die Entstehung der alexandrinischen Schule. ZKG. 71, 1-25: 193-214.

25. Jacobsen A.-C. 2003. Origen on the Human Body. Origeniana VIII. Origen and the Alexandrian tradition. Ed. L. Perrone. Vol. I-II. Leuven, University press, 649-656.

26. Nautin P. 1977. Origene. Sa vie et son oeuvre. Paris, Edition, 474.

27. Origen. Commentary on the Gospel of Matthew. 2019. From Ante-Nicene Fathers, Vol. 9. Ed. by Allan Menzies. Buffalo, NY, Christian Literature Publishing Co. http://www.newadvent.org/fathers/1016.htm

28. Runia D. 2003. Origen and Hellenism. Origeniana Octava. Origen and the Alexandrian tradition. Ed. L. Perrone. Vol. I-II. Leuven, University press, 43-48.

29. Scott A.B. 1991. Origen and the Life of Stars. Oxford, University Press, 189.

30. Theiler W. 1966. Ammonios der Lehrer des Origenes. Forschungen zum Neoplato-nismus. Ed. by W. Theiler. Berlin, de Gruyter, 1-45.

31. Williams R.D. 1999. Origen between Orthodoxy and Heresy. Origeniana Septima. Leuven, $3-14$.

\section{Ссылка для цитирования статьи Link for article citation}

Зайцева И.В. 2020. Осуждение оригеновского учения о предсуществовании и переселении душ в IV-VI вв. Via in tempore. История. Политология, 47 (2): 259-268. DOI 10.18413/2687-0967-2020-47-2-259-268.

Zaitseva I.V. 2020. Condemnation of the doctrine of Origen about the pre-existence of souls and reincarnation in the IV-VI centuries A. D. Via in tempore. History and political science, 47 (2): 259-268 (in Russian). DOI 10.18413/2687-0967-2020-47-2-259-268. 